Journal of Sustainable Development of Transport and Logistics

journal home page: https://jsdtl.sciview.net

Težak, S., \& Lep, M. (2019). Solutions for increasing the capacities of cable cars. Journal of Sustainable Development of Transport and Logistics, 4(1), 31-37. doi:10.14254/jsdtl.2019.41.4 .

\title{
Solutions for increasing the capacities of cable cars
}

\section{Sergej Težak, Marjan Lep}

University of Maribor,

Faculty of Civil Engineering, Transportation Engineering and Architecture, Department of Transportation Engineering,

Smetanova 17, 2000, Maribor, Slovenia

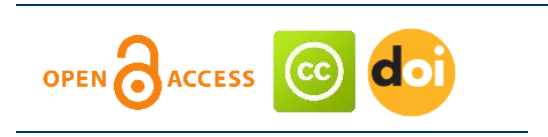

Article history:

Received:March 5, 2019

1st Revision: March 22, 2019

Accepted: April 27, 2019

DOI:

10.14254/jsdtl.2019.4-1.4

\begin{abstract}
Cableways have some potential to be used in urban public transportation, particularly uni-directional aerial cable cars with circulating cabins, called gondolas. They have several advantages, but two major problems must be solved: the capacity and the operating speed are not competitive when compared to other means of urban mass transport because of boarding procedures and slowing down and accelerating on intermediate stations. In this paper constructional solutions are presented. Boarding takes place on at least two platforms; these could be on the same level or on separate levels. At intermediate stations certain cabins are diverted to the extra platform while the majority of cabins travel with unreduced speed. Following this constructional approach, the nominal capacity of gondolas could be doubled while increasing the operational travel speed on lines with lot of intermediate stops.
\end{abstract}

Keywords: gondola, public transport, dwelling time, platform, geometric modeling.

\section{Introduction}

Cableways are transport devices to carry passengers by rope, usually electrically powered, but are rarely used in urban areas. Cable car transport is carried out using aerial cable cars, surface lifts, and funiculars (Doppelmayr, 1997). Ski lifts and funicular railways carry passengers on the ground level; with aerial cable cars, passengers are carried in the air. For this reason, aerial cable cars are more suitable for use in urban environments because they do not burden existing urban traffic routes.

According to operating principles, aerial cable cars are divided into aerial tramways and gondolas. Aerial tramways (jig-back ropeways, reversible aerial ropeways) transport passengers using one or two cabins that move back and forth on cables. Their maximum speed is $12 \mathrm{~m} / \mathrm{s}$ or $43.2 \mathrm{~km} / \mathrm{h}$ (CEN 2004) and they have maximum capacities of up to 2,000 persons/h.

Gondolas are uni-directional aerial cable cars with circulating vehicles (cabins). They consist of several cabins that can carry up to 30 persons each and have greater capacities than aerial cars, up to 4,000 persons $/ \mathrm{h}$. The speed is slower than aerial cars, with a maximum of $7 \mathrm{~m} / \mathrm{s}$ for bi-cable gondolas

Corresponding author: Sergej Težak

E-mail: sergej.tezak@um.si

This open access article is distributed under a Creative Commons Attribution (CC-BY) 4.0 license. 
and a maximum of $6 \mathrm{~m} / \mathrm{s}$ for monocable gondolas (CEN 2004). Passengers do not need to wait for the vehicles at the station, as the vehicles constantly come and go. The spans between the pylons are smaller than aerial tramways because there is more than one vehicle on the rope at a time and the lengths of gaps and precipices over which cabins can travel are smaller than for the aerial tramways. When at a station, cabins do not stand still but move slowly through the station, which can make it difficult for persons with disabilities and older adults to enter. Time of entry into the cabin is limited depending on the speed and length of the platform. Gondolas are more suitable for public passenger transport, which requires high capacity. The speeds of cable cars are low but, in the case of gondolas, the vehicles come constantly into stations and passengers do not need to wait for them.

The problem is that these cableways and gondolas do not have a large capacity for the transport of passengers. It is clear that the capacities of aerial cars are not competitive with the existing, moreused modes of passenger transport in urban centers. According to the Transport Research Board (2003), the types of public transport commonly used in urban centers have much higher capacities. Heavy rail can transport up to 49,000 persons/h, metro up to 36,000 persons/h and even light rail on streets (trams) can transport up to 11,800 persons/h. Buses on dedicated lines have a capacity up to 10,000 persons/h. These capacities may vary under different conditions of use, but they are much greater compared to the capacities of aerial cable cars.

The purpose of this article is to present new construction solutions for increasing the operational capacity of cableways, so that this mode of transport becomes more competitive compared to the other types of passenger transport in urban areas. The problem to be solved is actually how to increase the amount of entering and exiting passengers per time unit in the terminal and intermediate stations.

\section{Literature review}

The uses of cable cars in non-urban environments, especially in mountainous areas and for tourism, have been well studied, but the use of these systems in urban areas and city centers as part of public transport networks have not. Technical solutions on cable cars are fairly well described in various books (Doppelmayr, 1997; Nejez, 2006). The issue regarding the uses of different types of cable cars and comparisons with other transport systems in an urban environment is presented in a study by ClementWerny et al. (2011).

Aerial cable cars have several advantages compared with other transport modes. Routes are independent of surface characteristics (steepness, infrastructure barriers), and the need for extra land for transport facilities is limited. Cable cars are powered by electricity, and thus emit fewer $\mathrm{CO} 2$ emissions and exhaust emissions if renewable energy is used for electricity. Noise emissions are significantly reduced. The level of traffic safety is high and the transportation is comfortable (vibrations occur only when vehicles pass over the roller batteries) (Težak, 2016). Despite their good characteristics, aerial cable cars also have certain limitations. The speed is limited and consequently the capacity is limited. Gondolas with intermediate stations are suitable only for distances up to $7 \mathrm{~km}$. They are not wind resistant, and can normally handle winds up to $18 \mathrm{~m} / \mathrm{s}(65 \mathrm{~km} / \mathrm{h})$, although bi-cable systems can handle up to $90 \mathrm{~km} / \mathrm{h}$. It is quite difficult to rescue people from aerial cable cars. Perhaps the most disturbing aspect is the negative visual impact of cable cars on urban landscapes (Težak, 2016).

In Medellin, aerial gondola lines were built for use in public transport. As Medellin is a representative example of the use of cable cars in public transport, this case has been discussed by many authors, including Heinrichs and Bernet (2014) and Brand and Dávila (2011). In other parts of the world, cable cars are used as parts of urban transport systems primarily for tourism purposes.

Dwell times for non-moving public transport vehicles (buses) were studied in Rexfelt et al. (2014). The average dwell time when the validation of tickets is done before entering the platform for a bus for 10 people is around 22 seconds and for 30 people around 43 seconds.

\section{Approach to the construction solutions}

The existing system of entry and exit of gondolas (Fig. 1) should be reconsidered. The existing system for gondolas uses only one platform for boarding. The vehicle has a maximum speed of $0.5 \mathrm{~m} / \mathrm{s}$, and the minimum distance between vehicles in a station is $0.5 \mathrm{~m}$ (CEN 2004). 
Figure 1: Existing system of gondolas - passenger entry and exit in station

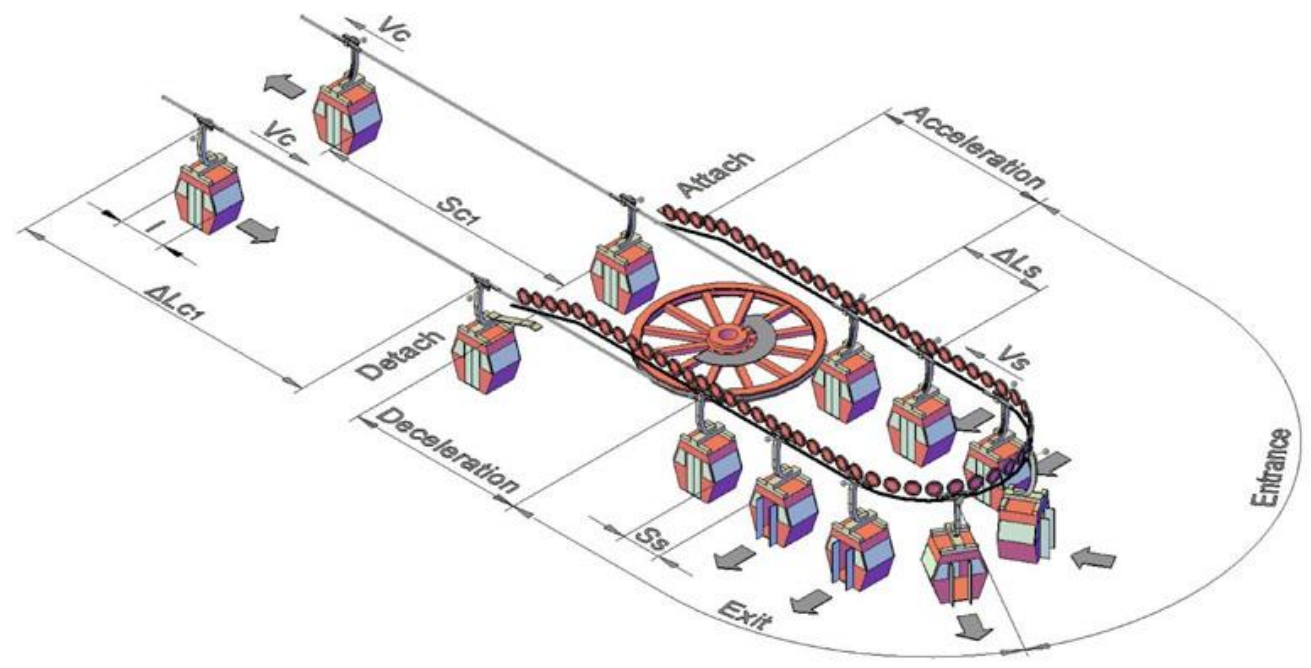

If a length of the vehicle is $3.0 \mathrm{~m}$, the minimum pitch (distance between suspensions) between vehicles in the station is $3.5 \mathrm{~m}$. On the base of the maximum speed of vehicles in the station $(0.5 \mathrm{~m} / \mathrm{s})$ and minimum pitch between vehicles in the station, the minimum time interval between vehicles is 7 seconds. As only one platform is in use, the minimum time intervals between vehicles in the station and on the line are the same (7s).

Maximum capacity of the gondola lift depends of the minimum interval between vehicles and number of persons in the vehicle (n). If we take into account that the number of persons in the vehicle is 8 , the theoretical capacity of gondola lift $\left(Q_{c}\right)$ is:

$$
\mathrm{Q}_{C}=\frac{3600}{\Delta \mathrm{t}_{C}} \cdot \mathrm{n}=\frac{3600}{7} \cdot 8=4114 \text { persons } / \mathrm{h}
$$

However, in the practice the minimum time interval of 7 seconds is not applied. The gondola lifts with the largest nominal capacity have time intervals between vehicles of somewhere around 12 seconds. For example, the gondola lift in Medellin has a capacity of 3,000 persons/h with 10 persons in one vehicle and the interval between vehicles is 12 seconds (Brand \& Dávila, 2011).

The pitch between the vehicles on the line depends on the relationship between the speed of the vehicles in the station and the speed on the line $\left(V_{C}\right)$.

$$
\Delta \mathrm{l}_{\mathrm{C}}=\frac{\Delta \mathrm{l}_{\mathrm{S}}}{V_{S}} \cdot V_{C}=\frac{3,5}{0,5} \cdot 6=42 \mathrm{~m}
$$

The calculated pitch between vehicles on the line of 42 meters is quite large. The existing gondola lifts, which have 12 seconds of interval between vehicles, have an even greater pitch between vehicles at 72 meters. The comparable distance between vehicles in road transport is much shorter. Also the time interval between vehicles on the line of ropeway, which is in the given case 7 seconds, is fairly large and is much greater than in transport by roads ( 2 seconds).

\section{Conclusions}

The 7-versus 12-second time interval between two consecutive vehicles should be reduced. This can be achieved by the reconstruction of platforms. 


\subsection{Two platforms on one level}

A system with two station platforms for gondolas is shown in Figure 2. Two platforms - one internal and one external - are placed at the same level. Each platform has a separate line for vehicle braking, transporting, and accelerating, and both platforms use the same zone for detaching and attaching grips on the rope. Cabin entry into the station for both platforms is at the same place, and when it detaches from the rope, it starts braking for the internal or external platform. Cabins alternate between the internal and external platforms.

Figure 2: System of two gondola platforms on same level - passenger entry and exit

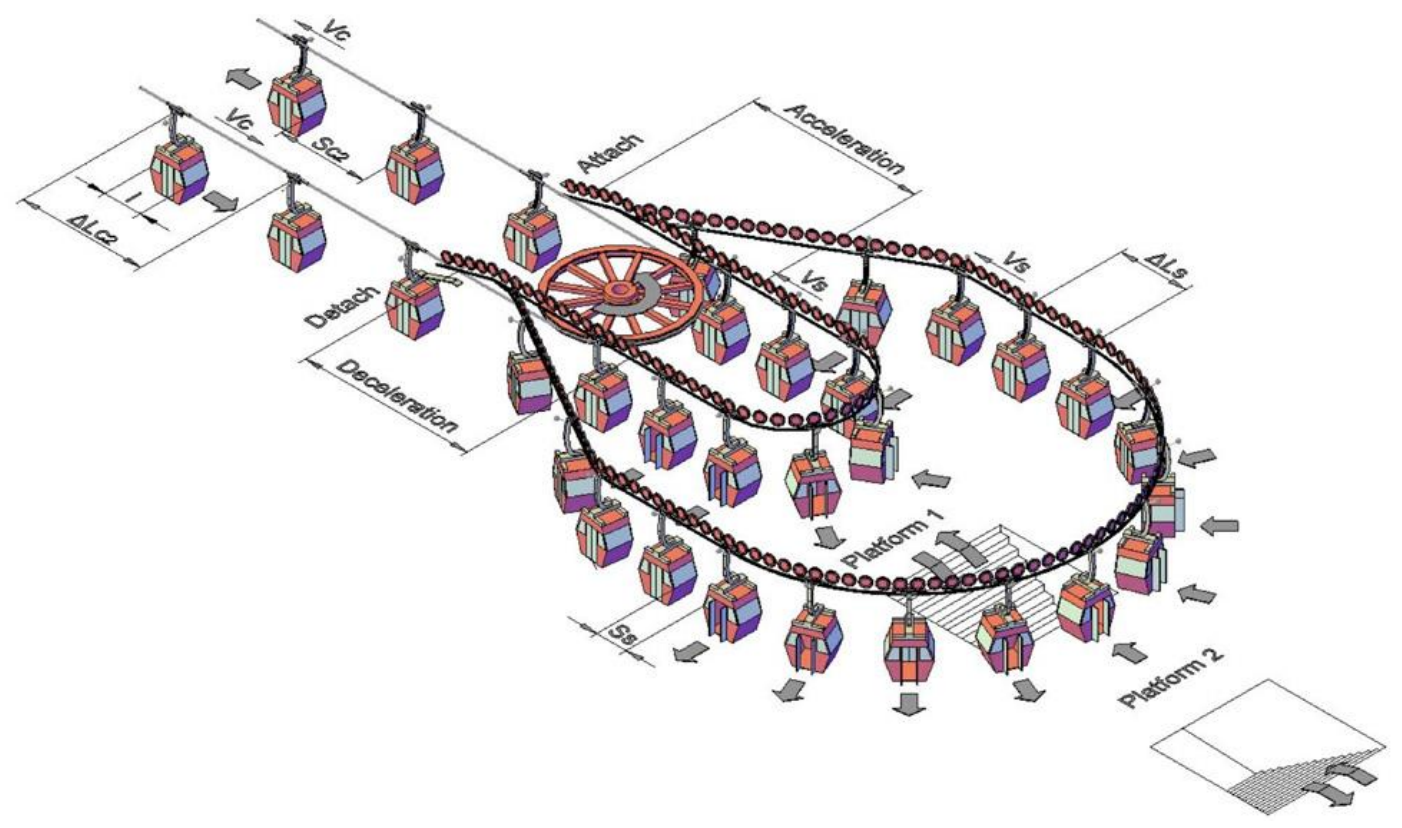

The procedure of entry into and exit from slowly-moving cabins takes place separately at the internal and external platforms, where the acceleration of the cabins is separate. Only before the zone of attaching the grips onto the rope, where the cabin has the same speed as the rope (VC), do the internal and external lines merge. All cabins leave the station at the same place. Passenger access to the internal platform runs through the underpass under the external platform.

This system could solve the problem of distances between vehicles that are too great on the line of the cable cars. In this case, vehicle speeds $(0.5 \mathrm{~m} / \mathrm{s})$ and minimum distances between vehicles $(0.5 \mathrm{~m})$ in each of the two platforms in the station are the same as for the existing system of gondolas with one platform. It also has the same minimum time interval between vehicles in the stations' platforms $(7$ seconds). However, with the use of two platforms in the station, the minimum interval between vehicles on the line is reduced twofold to 3.5 seconds.

\subsection{Two platforms on different levels}

Weaknesses of the system with both platforms on the same level (Figure 2) could be removed by using two platforms on two different floors, as shown in Figure 3. Each floor would have separate lines for the braking, transporting, and acceleration of cabins. In this case, the surface of the ground plan in the station would be smaller. 
Figure 3: System of two platforms for gondolas on two different floors - passenger entry and exit

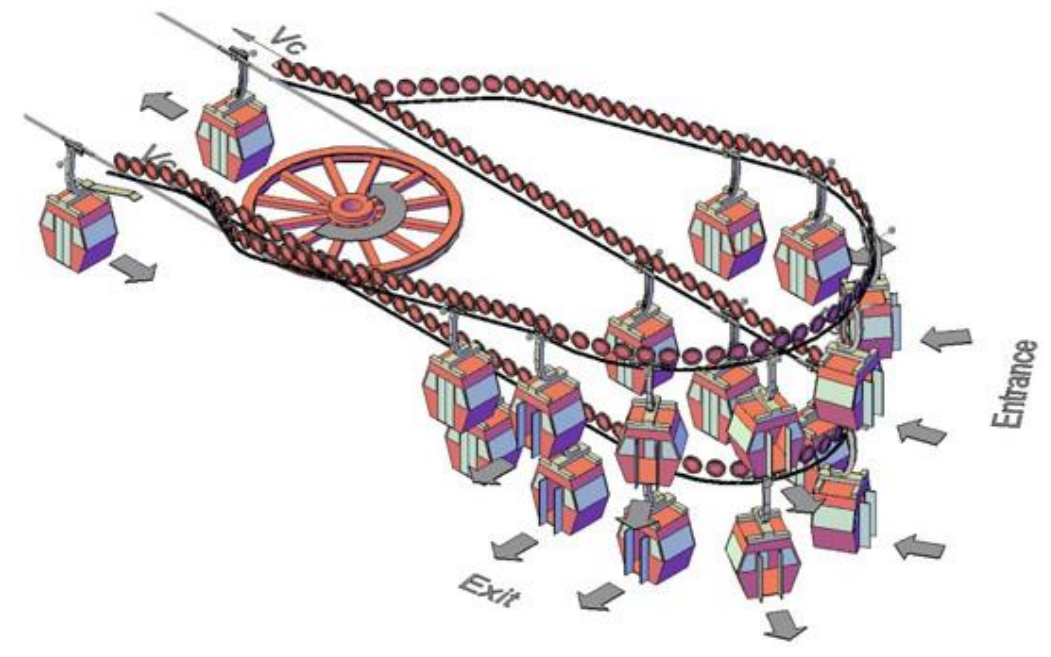

\subsection{Intermediate stations}

Another advantage of gondolas is that they use small vehicles. This means that in the intermediate stations on the line, it is not necessary to stop all cabins, only those from which passengers exit. Special construction of intermediate stations, as shown in Figure 4, could allow this. Using this measure, passengers in other cabins could smoothly travel to other or final stations.

Figure 4: Existing system of gondolas - passenger entry and exit in station

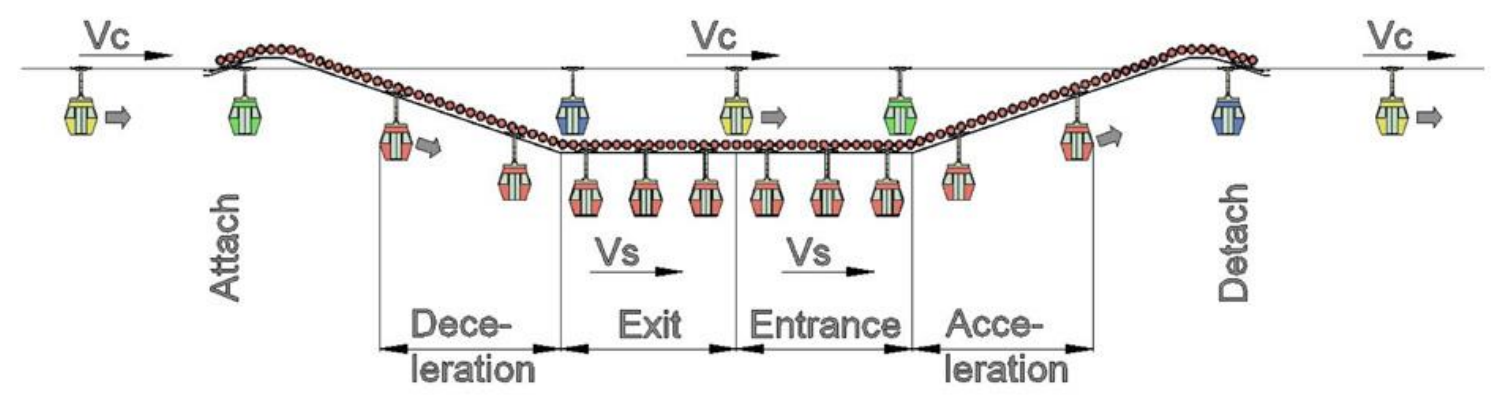

\section{Analysis}

With the use of two platforms in the station, the minimum time interval $\left(\Delta \mathrm{t}_{C 2}\right)$ between vehicles on the line is cut in half to 3.5 seconds. The pitch between the vehicles $\left(\Delta \mathrm{l}_{\mathrm{C} 2}\right)$ on the line is reduced to 21 meters. The capacity of gondola lifts with two platforms in the station $\left(\mathrm{Q}_{C_{2}}\right)$ shall be increased by two times and in this case is:

$$
\mathrm{Q}_{C 2}=\frac{3600}{\Delta \mathrm{t}_{C 2}} \cdot \mathrm{n}=\frac{3600}{3,5} \cdot 8=8228 \text { persons } / \mathrm{h}
$$

Nominal capacities of gondolas with two platforms are much higher compared with other options of cable car transport, as shown in Fig. 5. 
Figure 5: Comparison between gondolas with two platforms and other types of cable cars
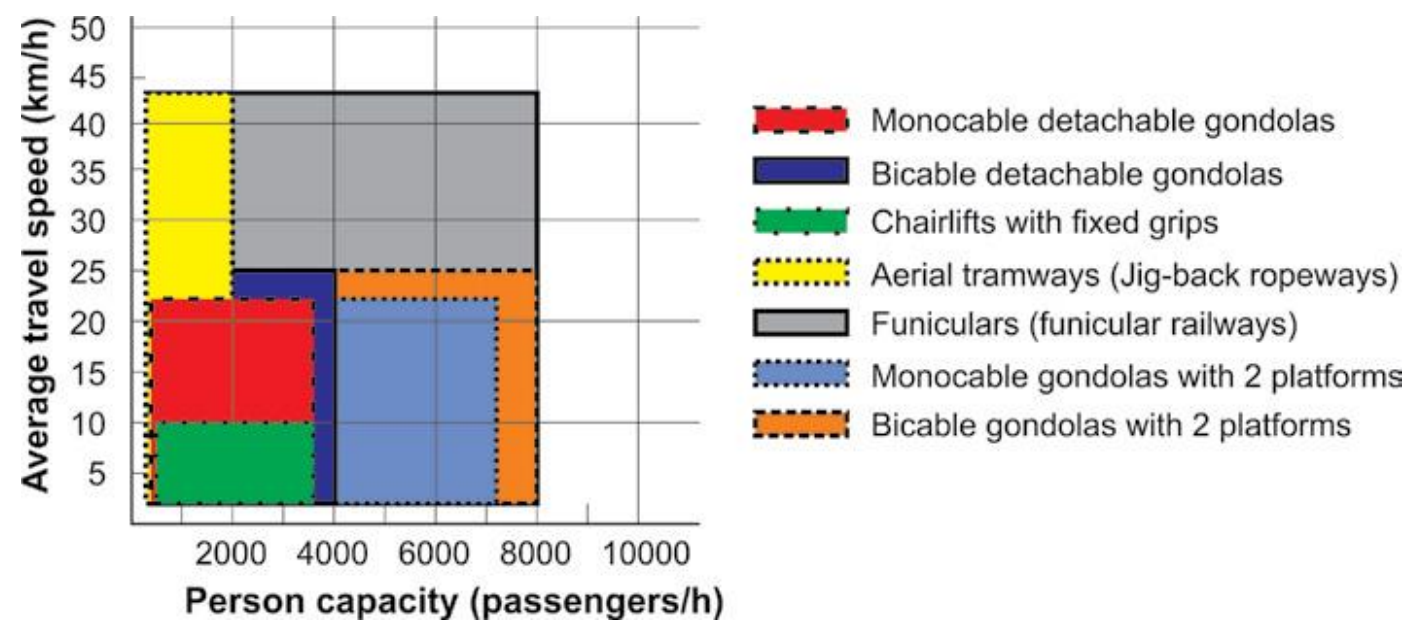

\section{Conclusion}

Cable car transport has many advantages compared with other modes of passenger transport, such as clean electricity, high levels of safety for passengers, and quiet operation. The most important characteristic is that cable car transport can be installed in the air over streets in urban areas, independent of congestion. However, cable cars, in spite of the advantages, still cannot achieve certain characteristics of other modes of transport, such as capacity or number of passengers per hour. This paper has demonstrated that cable car transport can become competitive with other types of passenger transport in urban areas. With additional platforms in gondola stations, it is possible to achieve reduced distance between vehicles on the line and increase capacity.

\section{Citation information}

Težak, S., \& Lep, M. (2019). Solutions for increasing the capacities of cable cars. Journal of Sustainable Development of Transport and Logistics, 4(1), 31-37. doi:10.14254/jsdtl.2019.4-1.4.

\section{References}

Brand, P., \& Davila, J. (2011). Aerial cable-car systems for public transport in low-income urban areas: lessons from Medellin, Colombia.

CEN, EN-12929-1. (2004). Safety requirements for passengers transportation by rope - General provisions - Part 1: Requirements for all installations. CEN/TC 242, AFNOR.

Clement-Werny, C., Dubois, D., Ruyet, A.L., Potier, M., Rousic, S., \& Schneider, Y. (2011). Aerial ropeways as urban transport systems. Certu-STRTMG-CETE,.

Doppelmayr, A. (1997). Denkanstosse zur Funktionserfühlung von Einseilumlaufbahnen, Projektierung und Konstruktion im Sicherheitsregelkreissystem, basierend auf der Analyse von Vorfällen, ISBN 3-9500815-0-X, Wolfurt, Austria.

Heinrichs, D., \& Bernet, J. S. (2014). Public Transport and Accessibility in Informal Settlements: Aerial Cable Cars in Medellín, Colombia. Transportation Research Procedia, 4, 55-67.

Nejez, J. (2006). Vorlesung aus Seilbahnbau. Technische Universität Graz, Graz.

Rexfelt, O., Schelenz, T., Karlsson, M., \& Suescun, A. (2014). Evaluating the effects of bus design on passenger flow: Is agent-based simulation a feasible approach?. Transportation Research Part C: Emerging Technologies, 38, 16-27. 
Transportation Research Board. (2003). TRB, Transit Capacity and Quality of Service Manual, 2nd edition [online: 2015-06-8]. Retrieved from http://www.trb.org/Main/Blurbs/

Težak, S., Sever, D., \& Lep, M. (2016). Increasing the capacities of cable cars for use in public transport. Journal of Public Transportation, 19(1), 1.-16.

Težak, S. (2012). Modern Cableways-The Base of Mountain Sports Tourism. In Strategies for Tourism Industry-Micro and Macro Perspectives. IntechOpen.

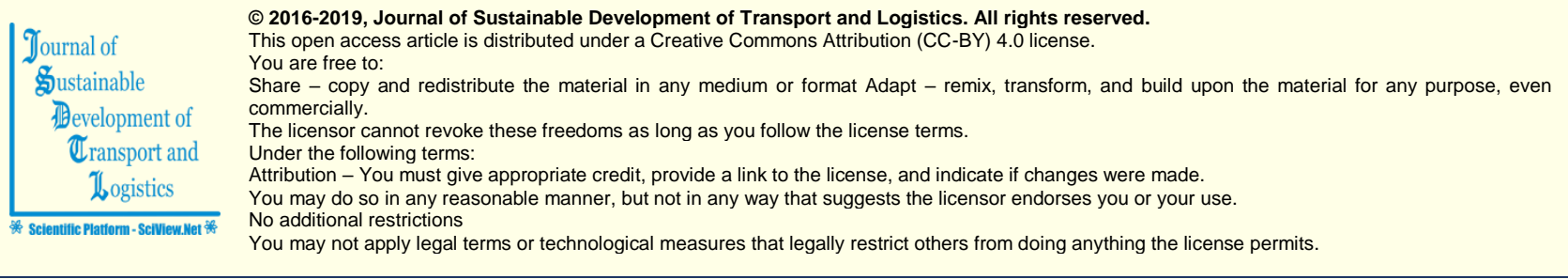

Journal of Sustainable Development of Transport and Logistics (ISSN: 2520-2979) is published by Scientific Publishing House "CSR", Poland, EU and Scientific Publishing House "SciView", Poland, EU

Publishing with JSDTL ensures:

- Immediate, universal access to your article on publication

- High visibility and discoverability via the JSDTL website

- Rapid publication

- Guaranteed legacy preservation of your article

- Discounts and waivers for authors in developing regions

Submit your manuscript to a JSDTL at https://jsdtl.sciview.net/ or submit.jsdtl@sciview.net 